\title{
AMULETO FÁLICO ROMANO HALLADO EN LA PUEBLA DEL RÍO (SEVILLA)*
}

\section{ROMAN PHALLIC AMULET FOUND AT LA PUEBLA DEL RÍO (SEVILLA)}

\author{
ÁLVARO GÓMEZ PEÑA**
}

Resumen: El presente artículo aborda el estudio de un amuleto fálico romano encontrado en superficie en el Pinar de la Marismilla, en La Puebla del Río (Sevilla) y sirve como punto de partida para hacer un análisis sobre el significado de los amuletos fálicos, en particular, y sobre la visión del falo, en general, en la Antigüedad romana.

Palabras claves: Amuleto fálico, Época Romana, mal de ojo.

\section{ESTADO DE LA CUESTIÓN}

Hasta hace poco tiempo, la bibliografía sobre amuletos fálicos o la mención de éstos en series de objetos de bronce o plomo ha sido muy escasa. Los motivos aducidos por los estudiosos son varios: el pudor a estudiar este tipo de objetos, la escasez de tales amuletos o el desconocimiento de la posesión de los mismos por parte de coleccionistas privados. No obstante, ya han existido intentos de clasificar los amuletos fálicos en función de

\footnotetext{
* Mi más sincero agradecimiento a los profesores José Luis Escacena Carrasco y José Beltrán Fortes, a Alberto Quiroga y a María de los Ángeles Jiménez Higuera por sus continuas y provechosas sugerencias en la elaboración de este trabajo. A todos les exonero de cualquier error en este artículo.

** Miembro del Proyecto Estuario. Análisis del poblamiento y secuencia cultural durante el Holoceno en la antigua desembocadura del Guadalquivir. Consejería de Cultura de la Junta de Andalucía.
}

Abstract: This article deals with the study of a Roman phallic amulet found in the area of Pinar de la Marismilla, in La Puebla del Rio (Seville) and serves as starting point for an analysis on the meaning of the phallic amulets, in particular, and the vision of phallus, in general, in Ancient Rome.

Key words: Phallic amulet, Roman Age, evil eye sus características físicas. La primera propuesta de clasificación fue llevada a cabo por Rolland (1965: 176181), creando cuatro tipos: falo visto de frente, falo visto de perfil, doble falo y triple falo. Dada su imprecisión surgieron posteriormente otras propuestas como la de Galve (1983), la de Zarzalejos, Aurrecoechea y Fernández Ochoa (1988), o la aquí utilizada de del Hoyo y Vázquez Hoys (1996) por parecernos la más extensa y precisa. Dicha propuesta no contempla sólo la tipología de los amuletos fálicos exentos con base en su aspecto formal, sino que inserta la misma dentro de una clasificación más amplia de representaciones fálicas que al fin y al cabo consideramos que tenían el mismo sentido socioreligioso. Afortunadamente, las publicaciones de dichos objetos, aunque de forma lenta, van viendo la luz. Sirva el presente estudio para que esta línea continúe, a la espera de que se realice un corpus que catalogue los amuletos fálicos romanos de la Península Ibérica. Corpus que se hace necesario. 


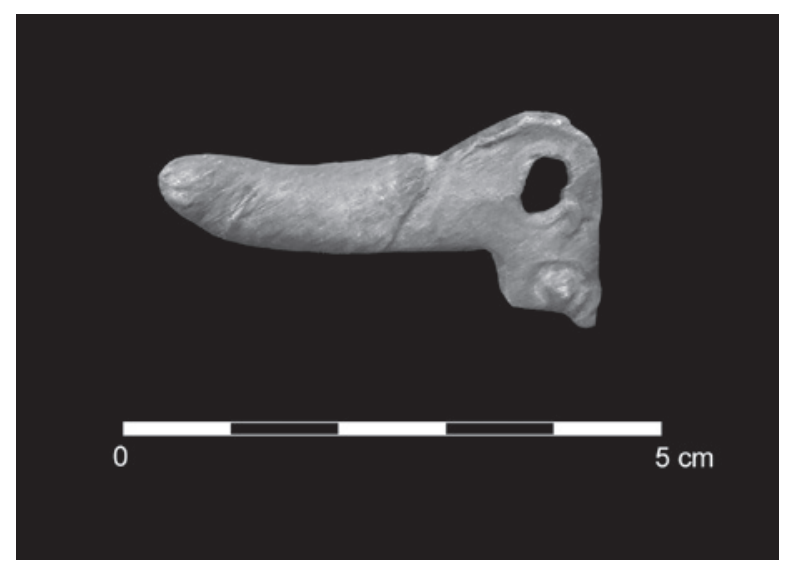

Figura 1. Amuleto fálico.

\section{ESTUDIO FORMAL DE LA PIEZA}

Siguiendo la clasificación de J. del Hoyo y A. M. Vázquez Hoys, el amuleto fálico de la presente publicación se describe como un amuleto fálico colgante, simple de perfil (VI, A, 2), en bulto redondo (Fig. 1) (Fig. 2). Es de plomo ${ }^{1}$, fundido en una sola pieza. El estado de conservación es bueno. Presenta un glande desmesurado en tamaño con respecto al tronco del falo, que es casi inexistente. La anilla es pequeña y no define una clara circunferencia separada del tronco del falo. El quebrado de la parte inferior hace pensar que existían unos testículos actualmente no conservados. También se observa en esta misma zona la rebaba del molde ${ }^{2}$. Mide $4 \mathrm{~cm}$ de largo, $2 \mathrm{~cm}$ de alto y $0.7 \mathrm{~cm}$ de anchura máxima (por la parte central). Pesa 10.5 gr.

\section{CONTEXTUALIZACIÓN DEL AMULETO}

Su hallazgo se produjo en superficie en el Pinar de la Marismilla (La Puebla del Río, Sevilla), zona en la que se ha documentado con bastante evidencia la existencia de poblamiento romano (Figs. 3, 4 y 5).

La conquista romana y la consecuente romanización del territorio trajo consigo un nuevo modo de vida basado en la explotación agrícola de tipo familiar

1. Existen otros amuletos fálicos hechos de oro que, probablemente, tuvieron un doble significado de diferenciación social y de mayor eficacia frente al mal de ojo dada la nobleza de este metal y los poderes atribuidos al mismo. Dos ejemplos de amuletos fálicos de oro han sido estudiados por Sáenz y Lasuén (2004: 221-227), y Johns y Wise (2003: 274-276).

2. Otro amuleto fálico en el que se aprecia la rebaba del molde es el 3.2 recogido por De la Barrera y Velázquez (1988: 212-214).

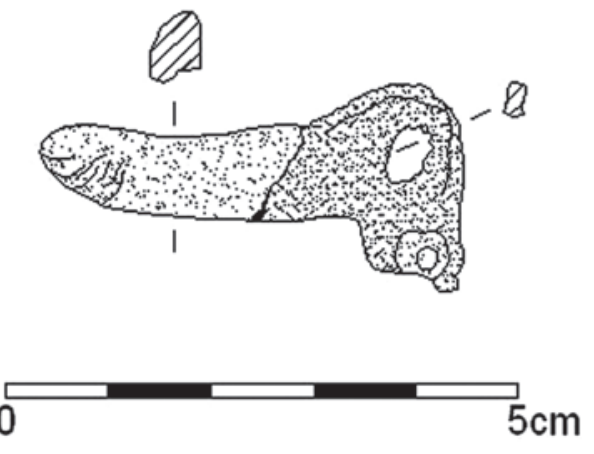

Figura 2. Perfil y secciones del amuleto fálico

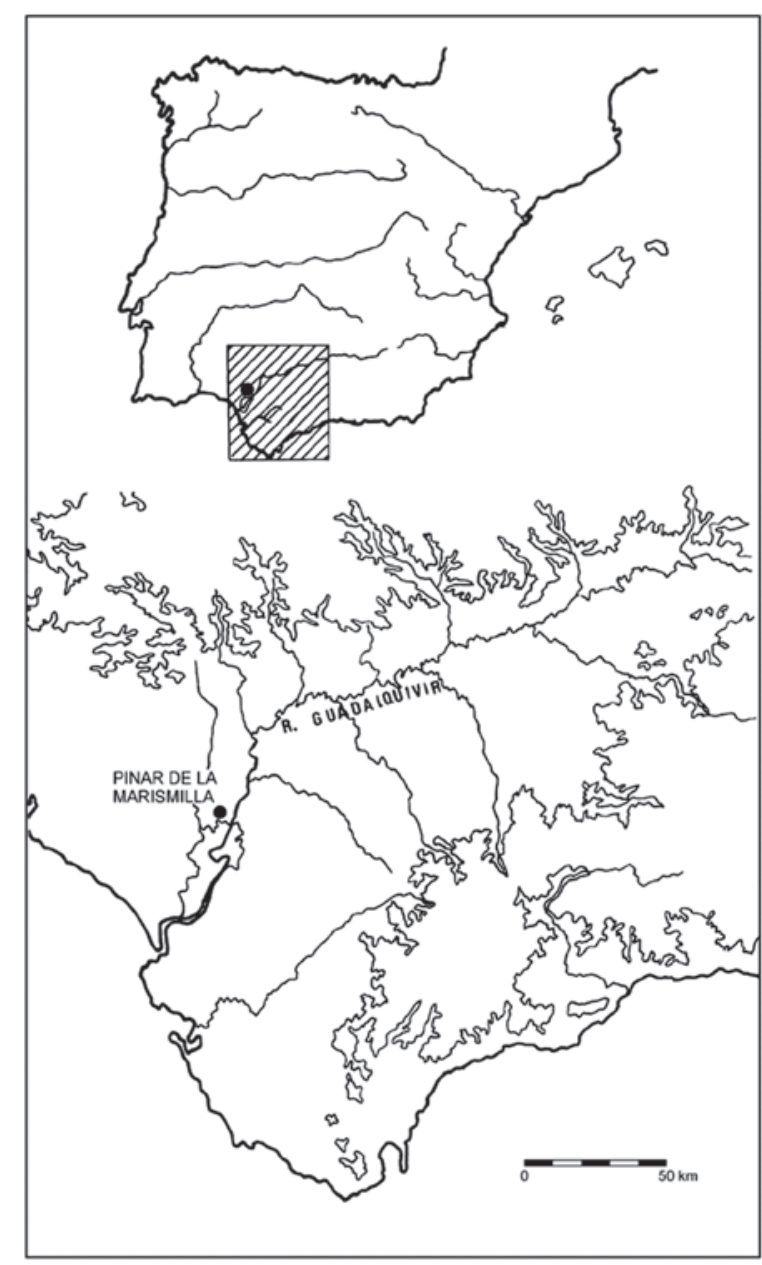

Figura 3. Situación geográfica del Pinar de la Marismilla. 
(villae). No obstante, en zonas urbanizadas desde tiempos prerromanos (Caura, Orippo...), como es el caso de los alrededores de La Puebla del Río, no hubo cambios esenciales ni en cuanto a la ordenación ni explotación del territorio al menos hasta el s. I d. C. dada su dependencia de Caura (actual Coria del Río).

Con el s. I d. C. se inicia el auge poblacional y económico de toda la zona, motivado por las políticas coloniales de César y Augusto, con el establecimiento de veteranos y la asignación de parcelas, así como una concentración de la propiedad fundiaria. Con ello se inició la explotación agrícola, sobre todo del olivo y la vid, como lo demuestran la difusión de marcas de ánforas por todo el Occidente europeo, prosiguiendo esta circunstancia en el s. II d. C., como muy bien apuntan Salas y Mesa (1996: 154).

Desde época de Trajano se produjo el final de la expansión territorial y, con ella, de la producción de excedentes, a lo cual habría que unir el aumento progresivo de la presión impositiva, que disminuiría la cantidad de excedentes comercializables, causas todas ellas que desembocaron en una regresión definitiva del comercio interprovincial. Todo ello propició el reforzamiento de los grupos económicos más poderosos frente a los grupos de medianos y pequeños propietarios, de tal forma que los poderosos hicieron sentir su predominio sobre el campo, dinámica que se acentuó durante el s. III d. C., produciéndose una disminución del volumen del comercio exterior, que se dejó ver en la interrupción de las exportaciones del

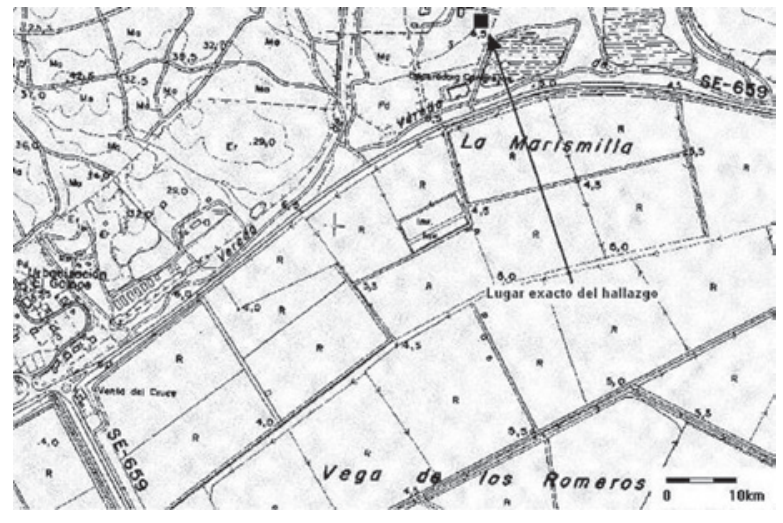

Figura 4. Plano de situación a escala 1:10000 de la zona del hallazgo del amuleto

aceite bético a Roma, así como un decaimiento de la vida urbana y una proliferación de las villae rurales.

Como muy bien observaron Salas y Mesa (1996: 156-157), la distribución espacial del poblamiento romano de esta zona se encuentra por encima de los $10 \mathrm{~m}$ sobre el nivel del mar, estando los yacimientos de carácter funerario separados de los asentamientos en zonas de posibles inundaciones en momento de subidas del nivel de las marismas. Estando toda la zona subordinada por la importancia de los cercanos núcleos de Caura, Hispalis y Orippo, que conforman un triángulo de ciudades portuarias en la desembocadura del Guadalquivir.

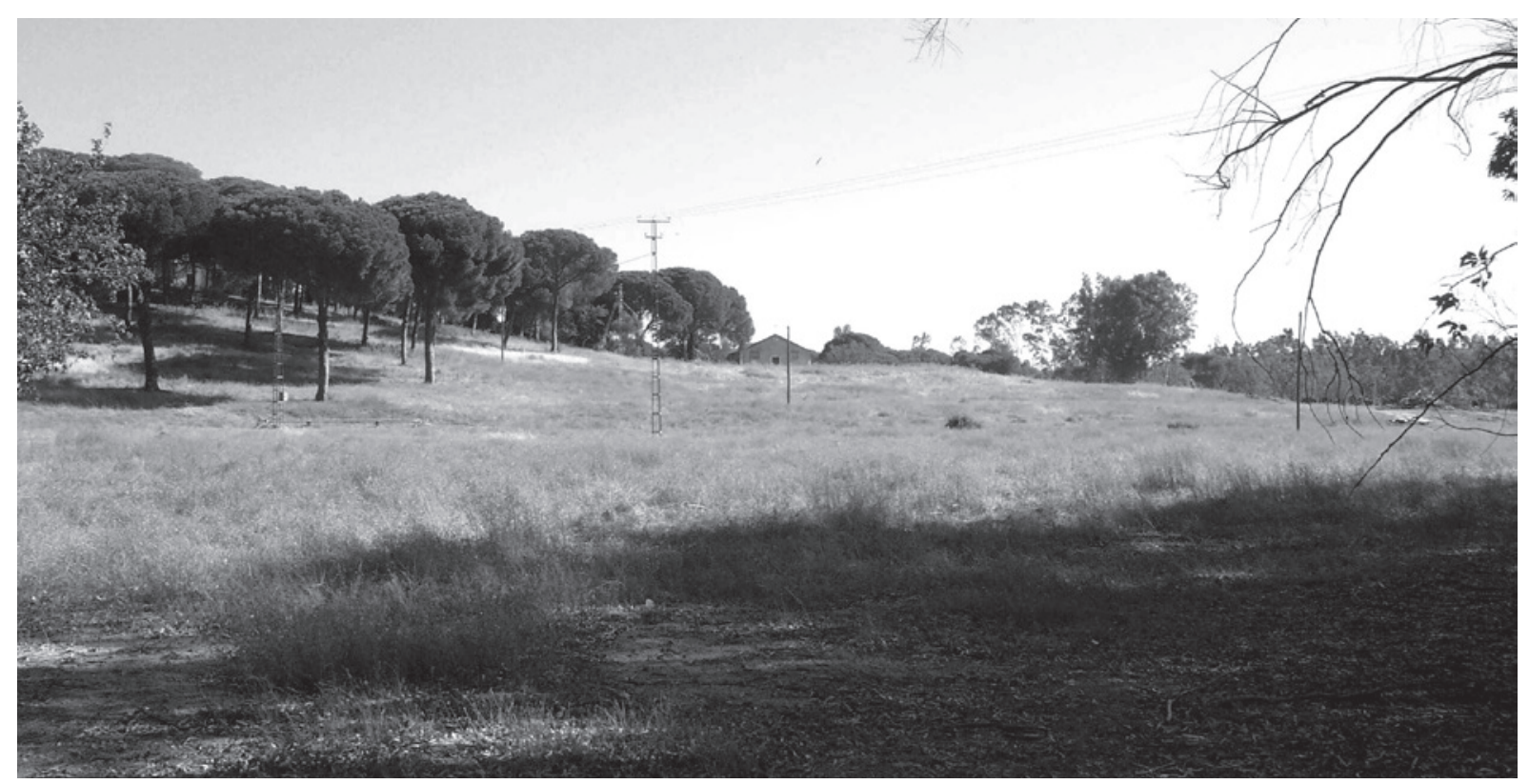

Figura 5. Fotografía del lugar exacto del hallazgo de la pieza 


\section{PERIODIZACIÓN DEL HALLAZGO}

Es difícil atribuir una cronología a estos objetos debido a que la inmensa mayoría de los amuletos fálicos que conocemos en la actualidad han sido hallados descontextualizados. Si bien es muy probable su datación en época romana dadas las características del lugar del descubrimiento y los paralelos existentes, no es posible dar fechas muy concretas. Ejemplares como el aparecido en Essex (Johns y Wise 2003) certifican su uso entre los siglos I y III d.C. o más concretamente en el caso del aparecido en Varea (La Rioja) (Galve 1983) podemos datar su utilización entre los reinados de Tiberio (14-37 d.C.) y Claudio (41-54 d.C.). No obstante, Varrón, en el siglo I a.C., y San Agustín, en el s. IV d.C. nos hablan de ellos, como veremos más adelante, por lo que su arco cronológico puede ampliarse.

\section{SIGNIFICADO Y USO DEL AMULETO FÁLICO EN ÉPOCA ROMANA}

Para entender el significado y uso del amuleto fálico en época romana consideramos imprescindible definir en primer lugar los conceptos a estudio. El término amuleto fue definido por Labatut (Daremberg y Saglio 1896-1929: 252-258) como "les objets extrêmement variés auxquels les anciens attribuaient le pouvoir de préserver soit des maladies, soit des maléfices, et en general de détourner toute influence maligne des persones ou des coses auxquelles ils étaient attachés". El propio Labatut recoge a pie de página que el vocablo amuletum parece tener su origen en Oriente, procedente de hamálet, "brazalete", "colgante"; de hamal, "llevar" en árabe; el primero en emplear el término amuletum/amuleta fue Plinio en su Historia $\mathrm{Na}$ tural $^{3}$, si bien el significado en Plinio designa la acción de colocarse un colgante o brazalete y no el colgante en sí. Sin embargo, ya con anterioridad Varrón comentaba en su Lengua latina (VII, 96-97) la conveniencia de utilizar amuletos como el que es objeto de estudio en el presente artículo para hacer frente a los peligros del fascinum (mal de ojo) ${ }^{4}$. En dicha obra, Varrón intenta buscar el origen etimológico de muchas de las

3. Plinio el Viejo escribió: "inter amuleta es editae quenque urinae inspuere" (Nat. Hist. XXVIII, 38), "tribuunt basilisco morborum remedia, veneficiorum amuleta" (ibidem XXIX, 66), "verpertilio si ter circumlatus domui per fenestram infigatur amuletum esse" (ibidem XXIX, 83).

4. Véase entre otras referencias para profundizar en la definición: Tupet (1976: 178-181) y Vázquez Hoys (1990: 140-160; 2003: 346-348). palabras latinas. La referencia concreta es recogida en la explicación del término obscaenum (obsceno): "Quare turpe ideo obscaenum, quod nisi in scaena palam dici non debet. Potest vel ab eo quod pueris turpicula res in collo quaedam suspenditur, ne quid obsit, bonae scaevae causa scaevola appellata. Ea dicta ab scaeva, id est sinistra, quod quae sinistra sunt bona auspicia existimantur"5.

Varrón comenta que los amuletos se cuelgan del cuello de los niños. Pero además de amuletos fálicos colgantes también existían anillos. Debido al tamaño tan pequeño de éstos, que están decorados con falos, se ha propuesto que los anillos y los colgantes podrían haber sido utilizados tanto por niños como por mujeres.

Nos ha resultado curioso observar que entre la bibliografía consultada no aparezca este párrafo completo y no se hable del término scaevola. Es cierto que Varrón en su obra tiene bastantes desaciertos al intentar averiguar el origen de los términos latinos (Hernández Miguel 2000: 15-22), pero al menos podría citarse en los estudios como una posible denominación particular del amuleto; posteriormente, San Agustín los denominará fascina, añadiendo que eran usados por niños y mujeres (Confesiones I, 7).

Ahondando, tras este pequeño inciso, en el asunto del mal de ojo, G. Lafaye define el concepto fascinum (un equivalente al griego baskania) en la obra de Daremberg y Saglio (1896-1929: 983-987) del siguiente modo: “...désignent en particulie le influence pernicieuse qu'une personne peut exercer sur tout ce qui l'entoure sans recourir à aucune cérémonie, à aucune formule magique, quelquefois même sans que sa volonté y soit pour rien. C'est là le caractère propre de cette actino funeste, ce lui qui la distingue de tous les autres maléfices. Elle est d'autant plus redoutable qu'elle est plus secrète, puisque celui-là même qui en est cause peut n'en avoir pas conscience". Por ello, los amuletos fálicos, al igual que otra serie de amuletos tanto en la esfera del mundo romano como en la Antigüedad en general (Vich 1990: 32-39; Vázquez Hoys 2003: 51-54), tuvieron en manos de quienes los usaban un carácter apotropaico y quizás profiláctico.

5. "Por esto, lo feo tiene el nombre de obscaenum por el hecho de que excepto en escena (scaena), no debe decirse públicamente. Puede deberse incluso al hecho de que a los niños se les cuelga en el cuello una cierta cosa algo fea, para que nada les dañe, denominada scaevola por razón de su buen augurio (scaeva). Ésta recibió su denominación a partir de scaeva, esto es "izquierda", porque las cosas que están a la izquierda, se consideran buenos auspicios". Traducción de Hernández Miguel, L. A. (1998): La lengua latina. Libros VII-Xy fragmentos, Biblioteca Clásica Gredos, Ed. Gredos, Madrid. Concretamente el texto citado se encuentra en las pp. 67-68. 
Dicha acción fascinadora, posiblemente motivada por la envidia o por algunos seres humanos con características no determinadas poco frecuentes en la vista (Rey 1989), tuvo un intento de explicación de manera racional por parte de Plutarco al decir que del cuerpo del fascinador, particularmente por sus ojos, emanaban unos efluvios malignos (Sympos. V, 7).

Pero, ¿cuál era el significado del falo en estos amuletos? Una de las explicaciones se basa en el carácter protector y viril que tenía el falo, característica ésta que hubiera significado en la Antigüedad la capacidad de la fuerza viril del pene para hacer frente al mal de ojo de manera simbólica. Esta idea explica la representación en amuletos fálicos de cabezas de toros, animal que evoca claramente la potencia (Tupet 1976: 178-181). Además, esta teoría se apoya en la posible introducción de los amuletos fálicos en la cultura romana por parte del ejército en contacto con las fronteras orientales (Daremberg y Saglio 1896-1929: 256), cobrando mayor sentido la simbología de virilidad humana y animal. Sin embargo, esta teoría no explica la aparición de lunas, sandalias puntiagudas y elementos vegetales con carácter preventivo ante la fascinación (Rey 1989: 234); la otra interpretación considera que el pene, o la higa/figa ${ }^{6}$ en otras ocasiones, era una imagen que por su carácter impúdico, apartaba la mirada del fascinador de los ojos de la víctima, neutralizándose el efecto y recogiendo el amuleto protector los efectos negativos del mal de ojo, y posiblemente devolviendo los mismos al fascinador. Esta idea viene apoyada por la consideración obscena del amuleto fálico comentada por Varrón y vista anteriormente, y necesitaría un estudio sin relación con los anteriores elementos simbólicos comentados.

Otras teorías explicativas no abordadas tomando como punto de partida los amuletos fálicos son: 1) en relación con los amuletos con ojos, la "inversión del símbolo" para J. E. Cirlot (1992: 57-62) como forma de actuar contra la mirada del fascinador. El ojo o los ojos del amuleto actúan de manera semejante a los ojos del fascinador. De ahí que el amuleto refleje los efluvios fascinadores hacia el aojador?; 2) otra teoría interpretativa es la realizada por Rey Seara según la cual, el falo como símbolo de fecundidad actuaría bajo la denominada "magia antipática" ya que para este autor la mirada del aojador

6. La higa/figa era un gesto que consistía en cerrar la mano con el dedo pulgar entre el índice y el corazón apuntándolo contra el "fascinador".

7. Resulta casi imposible rastrear el origen de la idea expuesta en este libro ya que la obra, de tipo ensayístico, carece de bibliografía y de notas a pie de página. No obstante, se puede ver en esta denominada "inversión del símbolo" otra manera de denominar a la "magia simpática", ya que "lo igual provoca lo igual". era propiciatoria de la detención de la fertilidad y destrucción de lo vivo (Rey 1989). Esta teoría explicaría la función fertilizante del falo en los amuletos y la aparición de animales parcialmente realizados en los mismos, pero no explicaría la aparición de lunas o sandalias en otros ${ }^{8}$.

La problemática de cómo abordar el estudio de los amuletos fálicos desde una perspectiva mágico-religiosa existe al intentar explicar desde una sola perspectiva todos los símbolos contra la fascinación. Los defensores del carácter viril del amuleto se apoyan en la magia simpática o simpatética (Frazer 2001), es decir, en la que la parte actúa como un todo, actuando el pene aisladamente (y de manera simbólica) como un ser dotado de la virilidad necesaria para hacer frente al fascinador. Por nuestra parte, consideramos que los amuletos fálicos han de ser estudiados como complemento de los elementos preventivos (tales como manojos de hierbas de tallos espinosos, sandalias puntiagudas, cornamentas varias). Con base en ello los amuletos fálicos serían el reclamo visual para atraer la atención del fascinador, siendo los cuernos e incluso la propia forma puntiaguda del pene erecto o de los penes arqueados hacia izquierda y derecha formando una luna los que actuarían como prevención puntiaguda.

Por ello proponemos desde estas líneas una nueva manera de enfocar el estudio de las prácticas mágicoreligiosas. Entendemos que sería interesante estudiar a los amuletos en general, y a los amuletos fálicos en particular, desde un punto de vista activo/pasivo. A diferencia de otras prácticas mágico-religiosas en las que las personas forman parte de manera activa en la experiencia, el propietario del amuleto es un individuo pasivo, siendo el falo el que actúa recogiendo de manera simbólica el mal que iba a sufrir.

\section{EL FALO EN LA ANTIGÜEDAD ROMANA}

Hemos visto hasta ahora el carácter apotropaico del falo en los amuletos. Pero la simbología fálica iba más allá de la mera representación en amuletos. El falo fue representado con el mismo carácter en vasos cerámicos cuya función y periodización es ciertamente problemática por la variedad de tipos, formas decorativas y fechas estratigráficas en que se han hallado (Mínguez Morales 1996: 305-319), en las murallas de las ciudades, en las esquinas de las casas y en los tintinabula que se colocaban en las puertas a modo de avisador para saber si alguien entraba o salía de las casas y comercios. Pensamos que estas representaciones comunitarias

8. Un amuleto en forma de lunulae aparece en De la Barrera y Velázquez (1988: 211-214). 
podían servir de amuletos gigantescos para proteger a toda una comunidad del miedo al mal de ojo en particular y de otros males en general (independientemente de que toda la comunidad o sólo una parte de la misma

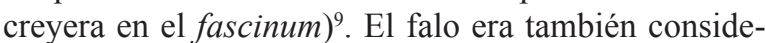
rado símbolo de fecundidad, siendo protector de los frutos. A ello obedece, en parte, el culto a Príapo. El Príapo primitivo personificaba el gran principio generador del universo. Los poetas señalan que este dios de amor carnal es hijo de Baco y Venus; es el resultado de los poderes generativos, activos y pasivos, de la naturaleza. El falo poseía unas proporciones desmedidas en las estatuas de Príapo. A esta deidad hay que sumarle otras como Pan, Silvano o Fauno. A la temática religiosa, hay que añadirle el carácter extendido y abierto del falo en la temática artístico-erótica en la Roma Antigua, pudiéndose contemplar escenas de sexo explícito con un amplio abanico de posturas, representándose tanto dioses como mortales, llegando a veces a la sátira (Blázquez y García Gelabert 1988).

Todos estos caracteres apotropaicos, religiosos, eróticos e impúdicos muy probablemente crearan en la mente de los romanos una esfera de alusiones simbólicas que en función de la experiencia personal de cada individuo le hiciera ser más partícipe del carácter erótico, del impúdico, o de otro de los arriba mencionados. Por tanto, pensamos que no se debe de confundir el conjunto general de alusiones simbólicas del falo en la Antigüedad latina con el carácter impúdico y simbólicamente cortante de los amuletos fálicos romanos en particular. No obstante, exponemos la idea de que quizás la solución no se encuentre en aunar criterios de todos los amuletos fálicos, como hemos expuesto más arriba, sino que el carácter simbólico de falos, lunulae o cuernos podría responder a fines distintos a los de la preservación del mal de ojo según los casos.

\section{BIBLIOGRAFÍA}

BLÁZQUEZ, J.M. y GARCÍA GELABERT, M.P. (1988): "Arte y erotismo en la Roma Antigua", Revista de Arqueología 83: 40-53.

CIRLOT, J.E. (1992): El ojo en la mitología. Su simbolismo. Ediciones Libertarias, Madrid.

DAREMBERG, M. C. y SAGLIO, E. (1896-1929): Dictionnaire des antiquités grecques et romaines: d'après les textes et les monuments. Librairie Hachette, Paris.

DE LA BARRERA, J.L. y VELÁZQUEZ, A. (1988): "Amuletos romanos de Mérida", Homenaje a Samuel

9. Idea recogida en el prefacio de Luck (1995). de los Santos: 211-214. Instituto de Estudios Albacetenses, Albacete.

DEL HOYO, J. (1996): “Amuletos fálicos inéditos de Uxama y Duratón”, Veleia 13: 259-263.

DEL HOYO, J. y VÁZQUEZ HOYS, M.P. (1996): "Clasificación funcional y formal de amuletos fálicos en Hispania", Espacio, Tiempo y Forma, Serie II, Historia Antigua 9: 441-466.

FRAZER, J.G. (2001): La rama dorada. Fondo de Cultura Económica, México.

GALVE, M.P. (1983): "El amuleto fálico con cabeza de toro de Varea (Rioja)", Caesaraugusta 57-58: 111-133.

HERNÁNDEZ MIGUEL, L. A. (2000): Varrón. Ediciones Clásicas, Madrid.

JOHNS, C. y WISE, P. J. (2003): “A Roman Gold Phallic Pendant from Braintree, Essex", Britannia 34: 274-276.

LUCK, G. (1995): Arcana Mundi: magia y ciencias ocultas en el mundo griego y romano. Ed. Gredos, Madrid.

MÍNGUEZ MORALES, J. A. (1996): “Decoraciones fálicas sobre vasos cerámicos de época romana de la Península Ibérica", Zephyrus 49: 305-319.

REY, E. (1989): "Notas sobre la fascinación en la antigüedad", Gallaecia 11: 229-238.

ROLLAND, H. (1965): Bronzes antiques de haute provence (Basses-Alpes, Vaucluse). CNRS, Paris.

SÁENZ, J. C. y LASUÉN, M. D. (2004): "El amuleto fálico de oro de Bilbilis (Calatayud-Zaragoza)", Saldvie. Estudios de Prehistoria y Arqueología 4: 221-227.

SALAS, J. de la A. y MESA, M. (1994): “Aproximación al poblamiento romano en la zona sur de la comarca sevillana del Aljarafe", Kolaios 3: 145-157.

TUPET, A. M. (1976): La magie dans la poésie latine. Belles Lettres, Paris.

VÁZQUEZ HOYS, A.M. (1990): "La Gorgona y su triple poder mágico", Espacio, tiempo y forma. Serie II, Historia Antigua 3: 140-160.

VÁZQUEZ HOYS, A.M. (2003): Arcana mágica. Diccionario de símbolos y términos mágicos. UNED, Madrid.

VICH, S. (1990): “Amuletos en la antigüedad: protección contra espíritus, encantamientos y hechicerías", Revista de Arqueología 111: 32-39.

ZARZALEJOS, M.; AURRECOECHEA, J. y FERNÁNDEZ OCHOA, C. (1988): “Amuletos fálicos romanos inéditos de las provincias de Madrid y Toledo", Cuadernos de Prehistoria y Arqueología de la Universidad Autónoma de Madrid 15: 301-316.

Fecha DE ENTRADA: 6-01-2009 FECHA DE ACEPTACIÓN: 7-11-2009 